\title{
The key role of knowledge-oriented leadership regarding to knowledge management practices in innovation performance of manufacturing and commercial companies of Guilan province
}

\author{
${ }^{1}$ Alborz Safari, ${ }^{2}$ Mohammad Raza Azadehdel \\ ${ }^{1}$ M.A student, Department of public management, Rasht Branch, Islamic Azad University, Rasht, \\ Iran \\ ${ }^{2}$ Faculty of management, Department of public management, Rasht Branch, Islamic Azad \\ University, Rasht, Iran
}

Corresponding Author: Alborzsafari@gmail.com; Reza-azadehdel@yahoo.com

\begin{abstract}
Keywords: knowledge-oriented leadership, innovation performance, knowledge management practices, commercial and manufacturing company
\end{abstract}

\begin{abstract}
In the new business environment that is characterized by turbulence and increasing complexity, the ability to establish and maintain a company's competitive advantage lies in its knowledge. The main objective of the study was to investigate the impact of knowledge oriented leadership on the innovation performance regarding to the role of knowledge management practices in manufacturing and commercial companies of Guilan province. The research is applied in terms of objective, and its methodology is descriptive. The population of study included manufacturing and commercial companies of Guilan province. To select a sample, convenience method was used .According to the Cochrane limited formula, total of 282 people were selected. Cronbach's alpha for reliability of the questionnaire was used. In this study, data were analyzed, by descriptive analysis, structural equation modeling and path analysis using SPSS 22 and Lisrel 8.50. Findings suggest that knowledge- oriented leadership has effect on creation of knowledge and application knowledge. Knowledge creation and application of knowledge has effect on the innovation performance. It was found that knowledge management practices has a mediating role in the relationship between knowledge -oriented leadership and innovation performance.
\end{abstract}

\section{Introduction}

International organizations based on the principles of knowledge management, development and implementation its plan to improve the effectiveness of business processes, increase productivity and quality of their service and find solutions and new products for their customers. In this regard, another important factor is leadership style and behavior that has a significant impact on the direction and effectiveness of knowledge management in organizations (Mohamed \& Nguyan, 2011). companies can use knowledge- oriented leadership to develop knowledge management practices and to imrove the willingness of employees in their innovation performance. Managers should establish the ideaj contextual conditions to propel and optimize the organization's use of knowledge management practices and initiatives through the design of tools such as human resource management practices (Lin, 2011).

Knowledge-oriented leadership is essential for technology-oriented organizations. It is an approach that is rapidly developing and attention to improve the effectiveness of processes, along with continuous innovation. Needing to knowledge leadership, derives from the fact that the knowledge practices on the innovation performance and access to sustainable competitive advantage is considered an important act. Indeed, leadership is as an essential condition for the development and knowledge management practices to encourage innovation objectives focuses on technology-intensive companies. In this regard, knowledge-oriented leadership is as a leadership issues and companies are considered successful that give more value(Donate $\&$ De pablo, 2014).

Innovation performance is combination of overall success of the organization in order to modernize and improve the result of the efforts made and the implementation of various aspects of 
innovation in the organization. In the literature, innovation performance is one of the most important drivers of other functional aspects of the organization regarding to the continuous efforts to improve, renew, exploration, learning from mistakes, compromise the competitive environment to quickly (Gunday et al., 2011). This concept can be achieved through exploratory innovation by reform of existing knowledge and skills development, customer needs and occur respond to environmental conditions (Zhou \& Wu, 2010). Innovation performance help to new product and process in organizations and considered as a competitive advantage (Xu \& Li, 2009). It is critical for companies to remain competitive and successful way to compete with market changes. The higher performance of enterprise innovation activities be related. Successful innovation can help companies achieve greater profits (Martinez, 2014). innovation performance is obtained for product development and new manufacturing processes or improving existing processes (Moradi et al., 2013).

Adopting new behavior and new idea or innovation to be taken in order to function (Tamay -Torres et al., 2010). Innovation performance is will often appear with the number of achievements, records and reports new projects that take part in routine work is claimed, will be displayed. Also, the quality of new products and new processes with rival represents the company's innovation practice (Hung, 2011). Companies quickly adapt to changes made possible through innovation performance created and are protected against environmental instability with regard to performance, profit increased their market participation (Zehir et al., 2012). Given the importance of weakness in innovation performance of manufacturing and commercial companies can be a unwillingness introduction of new products or services and the introduction of new process, not having respond quickly to introduce new competitive process, lack of adequate training for new service innovation and reduce the number of products offered in the market ( Kazazi \& Scholl, 2013).

Knowledge-oriented leadership is defined as any attitude or action- joint or individual, observed or imputed- that prompts new and important knowledge to be created, shared, and utilized in ways that bring a shift in thinking and collective outcomes. (Mabey et al., 2012). knowledgeoriented leadership implies role of knowledge management practices of companies in order to realize the opportunities for innovation (Donate $\&$ de pablo, 2014). Leaders must act as a advisor so that employees can recognize how knowledge management practices and job help them guaranty communications. Communications is vital for leaders to clearly show their expectations of the company and eliminate communication barriers (Schermehorn, 2012).

In this research, knowledge management practices are included two dimensions. Knowledge creation makes a stronger commitment in R\&D activities and are useful for creative learning experiences (Von Krogh et al., 2012). Application knowledge should focus on the integration and use of knowledge for organizational activities and solve problems more easily and effectively (Zack et al., 2009).

Knowledge-oriented leadership behavior and innovation performance regarding to knowledge management practices is necessary for technology intensive organizations in order to improvement of innovation performance through development and implementation of knowledge management practices. Knowledge-oriented leadership as a driving force for knowledge management measures that are indirectly linked with innovation performance. In fact, the leadership is broader knowledgebased company, has developed knowledge management practices, which in turn affects the performance of innovation. (Donate \& De pablo, 2014).

According to background conducted similar studies in the field have been the subject of research. Mohammadi Hossieni and et al (2013) conducted a study titled on the role of organizational learning in innovation performance increased. The effect of organizational learning and impact on innovation performance in enhancing the innovative performance elements of learning has taken place.

The population of the investigation are all supervisors and employees Industrial Co. Caspian seal is the sample number is 400 people, according to Morgan, and the results have a positive impact, direct and meaningful innovation performance of showed learning . Khalifeh Soltani et al (2010) examined the role of leadership in increasing the effectiveness of their knowledge 
management practices. The survey among 950 executives Iranian Oil Products Distribution Company in which 270 people were selected. The results showed a direct relationship between leadership styles with the creation and sharing of knowledge was performed. Effect of modulators on shared leadership and innovation performance significantly. Donate and De pablo (2014) as the leading knowledge-based research on knowledge management and innovation activities carried out The study consisted of 802 senior managers of the company in Spain that the sample of 111 questionnaires. The results showed that knowledge management practices as a mediator role in the relationship between the leadership, knowledge-oriented and innovation performance.

\section{THEORETICAL AND CONCEPTUAL MODEL}

\subsection{Performance Innovation}

The process of innovation performance in the application of new or improved services and delivery of products or technology to increase efficiency is concerned and in terms of the introduction of new or significantly improved process will be measured. Innovation performance according to the introduction of new methods or improve existing methods of how to work, how to organize and establish the effectiveness and efficiency of defined channel foreign cooperation to increase the company's internal operations. According to the introduction of new or improved organizational innovation performance in job training or internal knowledge sharing, flexible work, supply management or the management of production, output specific tasks and relationships with suppliers, customers or government measured. Marketing innovation performance is referred to introduce new or improved methods that help to the effectiveness of the service or cognition customers in terms of sales and marketing (Cho et al., 2011). Today, companies that focus their innovation performance, market share and profits to significantly increase (Moradi et al., 2013).

\subsection{Knowledge-oriented leadership}

Knowledge-oriented leadership rather than the position of the association focused, innovative learning processes and of the influence of subjective knowledge exchange, implicit and explicit support over time (Peet, 2012). Knowledge-oriented leadership is defined as the process by which individual members of other groups supporting the learning cycle needed to achieve the goals of a group or organization. Knowledge leadership may develop mechanisms to respond and control the sharing of knowledge with customers to help. Knowledge-oriented leadership is defined as the process by which individual members of other groups supporting the learning cycle needed to achieve the goals of a group or organization. Leadership development mechanism for accountability and control possible knowledge sharing with customers help (Yang et al, 2014). The emergence of knowledge led to conflicts parametric range can be aligned field. The term knowledge management, has been established in the past two decades. The researchers acknowledged that the concept of a knowledge-oriented leader in the true sense is not very well known. This type of leadership as a new paradigm for the entire field of knowledge management has been proposed. In most cases, it can be argued as an alternative view to managing and understanding until the new base for general principles (Huvila, 2014).

\subsection{Knowledge management practices}

Knowledge management practices are set of activities and strategies that companies use to improve organizational performance, knowledge creation, storage, transfer and operate. In this paper, two cases of knowledge creation and application of knowledge taken into consideration. According to the definition of the principle of acquired experience and skills of employees. When knowledge is created when people find new ways of doing things or develop essential knowledge. Knowledge of social interaction and cooperation organization (philanthropist et al., 1393). To create knowledge, knowledge- oriented leadership creates condition that leads to a stronger commitment to R \& D activities for innovative learning and be tested (Von Krogh et al., 2012).

Application of knowledge on the integration and application of knowledge to solve easier problem and the effectiveness of its organizational activities focused( Zack et al.,2009). The ultimate goal of 
knowledge management, application of knowledge to improve the performance of the organization. Knowledge will be invaluable when applied to (Nikookar et al., 2014).

In the literature we have to admit that the leadership is broader knowledge-oriented companies, knowledge management practices will be developed and therefore affect the performance of innovation. Knowledge leadership behavior must lead knowledge management within the company. Knowledge- oriented leaders with the support of channel development and knowledge management efforts, they make use of style, motivation, communication and promotion recruitment and leads the company's innovation performance (Donate \& De pablo, 2014). Knowledge-oriented leaders act in a way that encourages learning by challenging their employees and encourage and institutionalize learning through the provision of incentives and training, fostering a culture of learning and fault tolerance and development of transfer, storage, affect knowledge creation ( Williams \& Sullivan, 2011.)

In general, using the conceptual model of literature can be found as follows:

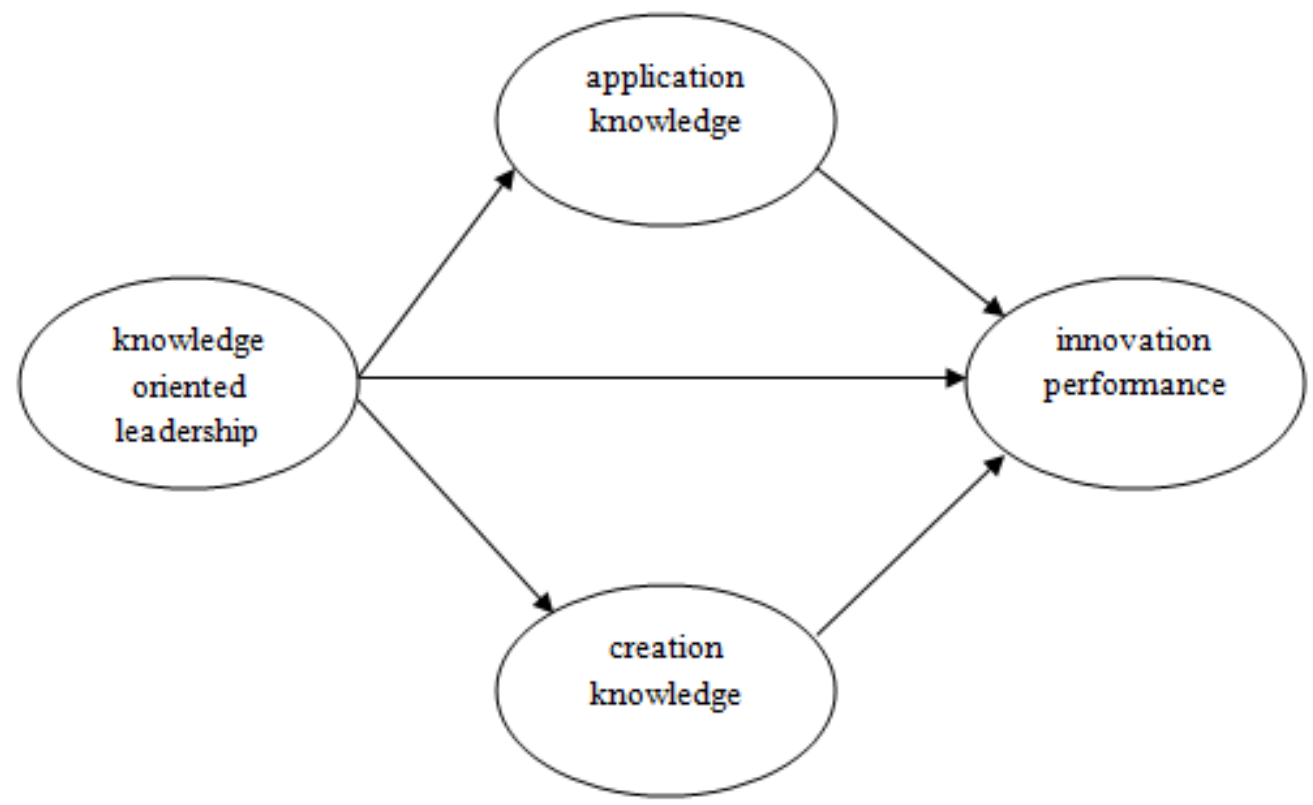

Fig. 1. Research model

\section{HYPOTHESES}

Based on the objectives defined hypothesis of the present study are as follows:

Hypothesis 1: knowledge creation has effect on innovation performance of manufacturing and commercial companies of Guilan province.

Hypothesis 2: Application of knowledge has effect on the innovation performance of manufacturing and commercial companies of Guilan province.

Hypothesis 3:, knowledge- oriented leadership has effect on creation knowledge of , manufacturing and commercial companies of Guilan province.

Hypothesis 4: knowledge-oriented leadership has effect on manufacturing and commercial companies of Guilan province.

Hypothesis 5: knowledge management practices has a mediator role in the relationship between of knowledge-oriented leadership and innovation performance of manufacturing and commercial companies of Guilan province.

Hypothesis 6:, knowledge-oriented leadership has effect on innovation performance of manufacturing and commercial companies of Guilan province. 


\section{METHODOLOGY}

The study is based on research design of descriptive and applied on the basis of objective and in terms of data collection, field. The implementation of the present study can be used to better understand the situation or to help the decision making process. Study to determine the variables describing the characteristics of a given position. The aim of the study is to describe the aspects of the phenomenon, the researcher with an individual vision, organization, attributes and so on (Skaran, 2013). In this study, structural equation modeling and path analysis using the software LISREL to analyze theoretical framework on assumptions. population of study include manufacturing and commercial companies of Guilan Province, and their number is about 2600. In this study, convenience sampling method was used. Because the number of manufacturing and commercial companies is limited, Cochran sampling formula used. One of the common tools for data collection is questionnaire. The study questionnaire has 20 questions.

Validity procedures designed according to the experts that were translated from foreign sources and after verification, was used. But what this study is to determine the reliability of the questionnaire used by emphasizing internal consistency, Cronbach's alpha coefficient is applied (Skaran, 2013). To calculate Cronbach's alpha reliability coefficient of the questionnaire to 30 managers of companies and have been calculated using SPSS 22 software.

\begin{tabular}{|c|c|c|}
\hline Research dimension & Number of questions & Cronbach's Alfa \\
\hline Creation knowledge & 7 & 0.764 \\
\hline Application knowledge & 5 & 0.801 \\
\hline Knowledge oriented leadership & 6 & 0.817 \\
\hline Innovation performance & 5 & 0.819 \\
\hline
\end{tabular}

\section{FINDINGS}

Before examining hypotheses, it is necessary to consider mean, standard deviation and variance.

\begin{tabular}{|c|c|c|c|}
\hline Variables & Mean & S.D & Variance \\
\hline Knowledge oriented leadership & 3.82 & 0.69 & 0.48 \\
\hline Application knowledge & 3.46 & 0.78 & 0.52 \\
\hline Creation knowledge & 3.55 & 0.77 & 0.59 \\
\hline Innovation performance & 3.73 & 0.71 & 0.51 \\
\hline
\end{tabular}

The situation with respect to both the standard and the significant estimates are as follows:

After the testing models, it is necessary to the structural model showing the relationship between latent variables investigation, to be provided. Using the structural model can be used to check the hypotheses. Structural model study was conducted using LISREL software version 8.5. The following chart shows the overall research on the standard estimate.

The next output coefficients and parameters obtained significant part of the overall study shows the measurement model. The significance test between the individual coefficients greater than 1.96 and 1.96 is smaller. It can be concluded that according to the significant numbers of coefficients and the relationships between variables all hypothesis were confirmed. Standard and T value model are shown respecively. 


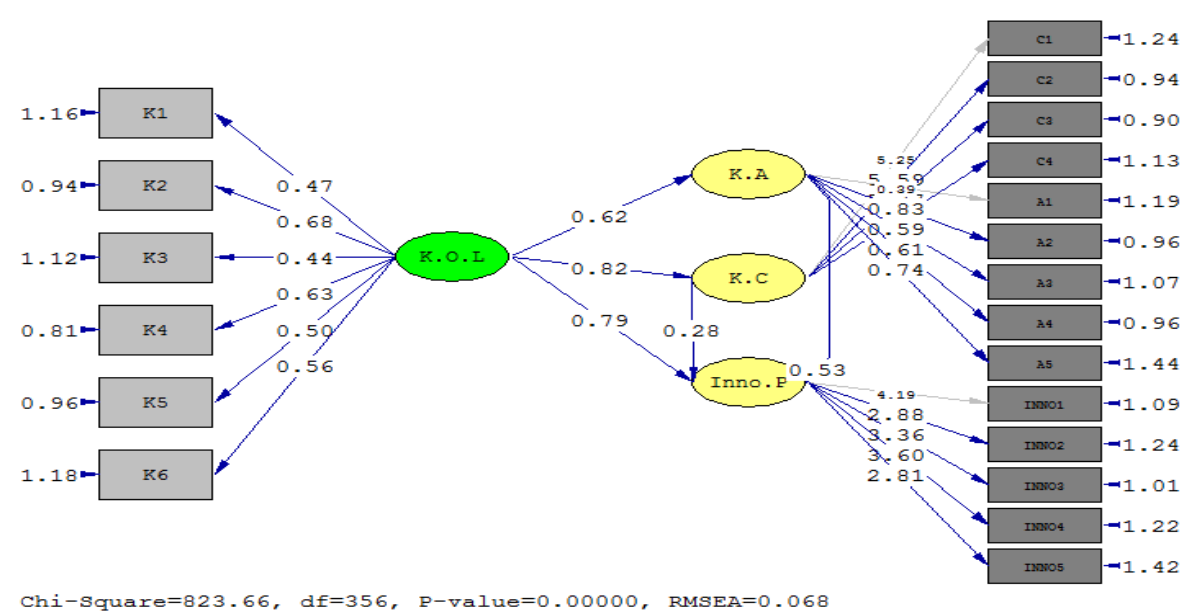

Chi-Square $=823.66, d f=356, \mathrm{P}-\mathrm{value}=0.00000, \mathrm{RMSEA}=0.068$

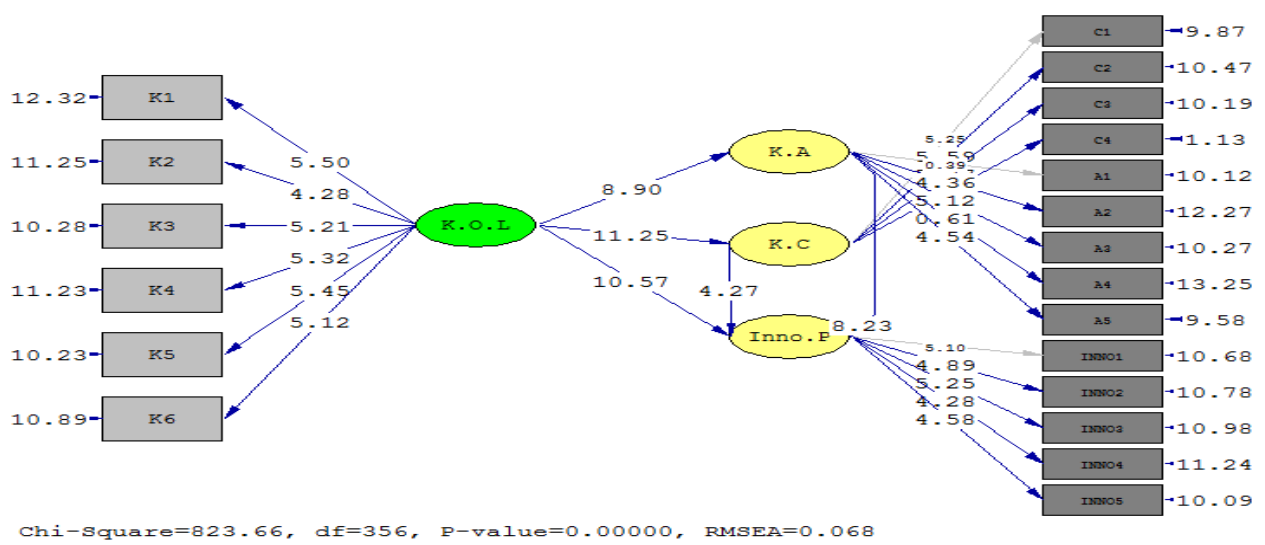

According to the base significant model, the t-statistic is equal to 4.27 and from there outside of the range [1.96 \& 1.96] denotes the hypothesis is confirmed. According to the standard model can be said that the relationship between knowledge creation and innovation performance is equal to 0.28 . In other words the creation of knowledge by 28 percent by the Guilan and commercial innovation in manufacturing firms are related. The second hypothesis about the impact of knowledge on innovation performance. According to the base model in significant research, the t-statistic is equal to 8.23 and from there out of range [1.96 \& 1.96] This hypothesis remains to be confirmed. According to the standard model can be said that in relation to the application of science and innovation performance is equal to 0.53 , in other words the application of science to the amount of $53 \%$ of the innovation performance in related manufacturing and commercial Guilan province. The third hypothesis is referred to the impact of the knowledge-oriented leadership on creation knowledge. According to the base significant model, the t-statistic is equal to 11.25 , and from there out of range [1.96 \& 1.96] denotes the hypothesis is confirmed. According to the standard model can be said that the relationship between knowledge creation and innovation performance is equal to 0.82 to 82 percent in other words a knowledge-based leadership is associated with knowledge creation. The fourth hypothesis about the impact of leadership knowledge. Due to the usage of the base model in significant research, the t-statistic is equal to 8.90 and from the outside of the interval [1.96 - \& 1.96] Contract This hypothesis is confirmed. According to the standard model can be said that the relationship between leadership, knowledge and application of knowledge is equal to 0.62 , in other words a knowledge-based leader in the 62 percent with the use of knowledge manufacturing companies Commercial

Guilan related. Fifth hypothesis related to knowledge management practices of mediator role in the relationship between knowledge- oriented leadership and innovation performance. According to the significant base model in , the t-statistic knowledge- oriented leadership with knowledge of the components of knowledge management practices and application of knowledge is confirmed as 
both out of range [1.96 \& 1.96] is located. According to the sixth hypothesis according to the Standard Model can be said that the relationship between knowledge management and innovation performance against the 0.79 is, in other words, knowledge leadership to the $79 \%$ of the innovation performance of manufacturing and commercial companies of Guilan linked and statistics $t$ is equal to 10.57. To investigate the impact of the direct and indirect effects of endogenous variables necessary to model in the table (1) is provided.

Table 1. Structural model: decomposition of effects

\begin{tabular}{|lc|c|}
\hline \multicolumn{2}{|c|}{ Path } & Direct and indirect effect \\
\hline Knowledge oriented leadership & application knowledge & $(0.62)$ \\
& & 8.90 \\
\hline Knowledge oriented leadership & creation knowledge & $(0.82)$ \\
& & 11.25 \\
\hline Knowledge oriented leadership & innovation performance & $(0.79)$ \\
& innovation performance & 10.57 \\
\hline application knowledge & innovation performance & $(0.53)$ \\
& & 8.23 \\
\hline creation knowledge & $(0.28)$ \\
& & 4.27 \\
\hline $\begin{array}{l}\text { Knowledge oriented leadership } \\
\text { performance }\end{array}$ & application knowledge innovation & $(0.33)$ \\
\hline $\begin{array}{l}\text { Knowledge oriented leadership } \\
\text { performance }\end{array}$ & creation knowledge innovation & $(8.23)(8.90)$ \\
\hline
\end{tabular}

\section{DISCUSSION AND CONCLUSION}

According to the analysis of the findings, it can be said as the impact of knowledge on innovation performance was confirmed, managers of companies, with a certain type of knowledgeoriented leadership for development and improvement of technology regarding to R\&D activities and convenient use of technology help innovation performance. Company's investment can effect on R\&D activities and experienced unit in order to development and improvement of technology. According to the findings of a study the impact of the application of knowledge on the innovation performance was confirmed. Also, access to relevant information and key knowledge and use of scientific knowledge used and the integration of different groups can lead to innovation performance. Managers by organizing knowledge and its application and use in different units from offer customers, vendors can play an important role in the application of knowledge. According to the analysis of the results showed that knowledge-oriented leadership has effect on knowledge creation. Because of weaknesses in the management of knowledge and innovation, leadership duties conform at issue in the assessment and external knowledge sharing and stored faced by managers.

Commercial and manufacturing companies can help to individuals who operate in R\&D activities through investment absorption in market. Since the findings of the study showed that the use of effective leadership, knowledge, managers should seek to establish a working group of experts from the sub-units of information terminals that if the problems encountered to help them through the integrated application of knowledge the knowledge to be solved. Company considering new ideas and changes, increasing their capacity to use scientific background to be able to have a sustainable competitive advantage over competitors in the innovation performance gain. According to analysis of the impact of research findings on innovation performance knowledge-oriented leadership was confirmed. Also, managers can plan using appropriate knowledge and learning through visual learning on how to do rival's products improvement. Manufacturing companies will also have to take advantage of new ideas to think about delivering products in accordance with the wishes and demands of their customers, and if otherwise, they can't compete with rivals. 


\section{References}

[1] Boroomand, M; Ranjbari, M.(2009). Strategic practices of human resource management and innovation performance: with emphasis on knowledge management role, Journal of human development, sixth, N24, pp.21-52.

[2] Cho, I; Park, H ; Choi, J. The impact of diversity of innovation channels on innovation performance in service firms, Serv Bus 5, Issue 3:, pp 277-294, 2011.

[3] Donate,J,M, Jesus D. Sánchez de Pablo. (2014)The role of knowledge-oriented leadership in knowledge management practices and innovation, Journal of Business Research, Volume 68, Issue 2, February, Pages $360-370$.

[4] Gholamreza, Kh (2010). Research methodology in management. Center of scientific publications Islamic Azad university.

[5] Gunday, G., Ulusoy, G., Kilic, K., \& Alpkan, L. (2011). Effects of innovation types on firm performance .Int .J .Production Economics, 133, 662-676.

[6] Huvila , I ( 2014). Towards information leadership, Aslib Journal of Info Mgmt , 66, 663-677.

[7] Hung, R. Y. Y., Lien, B. Y. H., Yang, B., Wu, C. M., \& Kuo, Y. M.( 2011). Impact of TQM and Organizational Learning on Innovation Performance in the High-Tech Industry. International Business Review, 20(2), 213-225.

[8] Khalife soltani, H; Hosseini,M, Asgari, N. (2010). Empowerment leadership style of knowledge management, Human resource quarterly university of Emam Hossein university, second year, N 2and3, pp. 149-166.

[9] Kazazi, A; Shol,A. (2013). The impact of TQM on innovation performance. Moderator role of organizational learning. Scientific research of management studies quarterly, N 71,pp.1-17.

[10] Lin, H. F. (2011). The effects of employee motivation, social interaction, and knowledge management strategy on KM implementation level. Knowledge Management Research \& Practice, 9(3), 263-275.

[11] Moradi, M; Valipoor, Y; Keykhosro, S. Abdollahiyan, F. (2013). Investigation of role of knowledge absorbsion capacity on innovative performance of organizations(Case study, pharmaceutical and insurance companies in Tehran).Journal of outlook business management, N13,pp. 10-79.

[12] Mohammadi, A; Amin bidokhti, A; Jamshidi, Laleh.(2014). Investigating role of organizational learning in increasing of innovation performance, Journal of innovation and value creation, N4,pp. 84-95.

[13] Mabey, C., Kulich. C. \& Lorenzi-Cioldi. F. (2012) Knowledge leadership in global scientific research, The International Journal of Human Resource Management, 23(12), 2450-2467.

[14] Martínez, F.J. Diaz-Garcia, C. and González-Moreno, A(2014). Environmental Orientation as a Determinant of Innovation Performance in Young SMEs, Int. J. Environ. Res., 8(3):635642,Summer ISSN: 1735-6865.

[15] Nikookar, Gh; Asgari, N; Gholami,M; Rahimi, E (2014). Role of intellectual capital in facilitating of knowledge management practices and public management N2, pp. 401-418

[16] Nguyen, H. N., \& Mohamed, S. (2011). Leadership behaviors, organizational culture and knowledge management practices: An empirical investigation. Journal of Management Development, 30(2), 206-221.

[17] Peet, M. (2012) Leadership transitions: tacit knowledge sharing and organizational generativity. Journal of Knowledge Management, 16, 25-60. 
[18] Schermerhorn, J. R.. Management (11th ed.). John Wiley \& Sons: New York, 2012.

[19] Shakeri,F,Mehrjoodi, M,H; Dehghan Dehnavi, H.(2010). Investigation of relationship of organizational atmosphere and innovation in process. Journal of scientific research of production and operational management N1, pp. 29-46.

[20] Tamayo-Torres, I. (2010). The moderating effect of innovative capacity on the relationship between real options and strategic flexibility. Industrial Marketing Management, Vol. 39, pp. $1120-1127$.

[21] Tarivardi, Y; Damchi jelodar Z.(2011). The relationship of risk management and performance of company, Journal of finanacial accounting and auditing. forth, N4, pp. 43-62.

[22] Von Krogh, G., Nonaka, I., \& Rechsteiner, L. (2012). Leadership in organizational knowledge creation: A review and framework. Journal of Management Studies, 49, 240-254.

[23] Williams, P., \& Sullivan, H. (2011). Lessons in leadership for learning and knowledge management in multi-organisational settings. The International Journal of Leadership in Public Services, 7(1), 6-20.

[24] Yang, P.Y. and Chang, Y.Ch. (2010). Academic research commercialization and knowledge production and diffusion: the moderating effects of entrepreneurial commitment. Journal of Scientometrics, 83(1): 403-421.

[25] Yang,L ,C- Huang, T Hsu.(2014). Knowledge leadership to improve project and organizational performance, International Journal of Project Management 32,40-53.

[26] Ying, H, M; Jian-peng ,W. (2013). The Impact of Shared Leadership on Innovation Performance, International Conference on Management Science \& Engineering (20th), Harbin, P.R.China pp 1385 - 1390.

[27] Zack, M., Mckeen, J. and Singh, S. (2009).“Knowledge management and organizational performance: an exploratory analysis", Journal of Knowledge Management, Vol. 13 No. 6, pp. 392-409.

[28] Zehira,C, Oznur Gulen Ertosunb, Zehirc,S, Müceldilli,B. (2012). Total Quality Management Practices' Effects on Quality Performance and Innovative Performance, International Conference on Leadership, Technology and Innovation Management, Procedia - Social and Behavioral Sciences $41273-280$.

[29] Zhou, K. Z., \& Wu, F.( 2010). Technological capability, strategic flexibility, and product innovation. Strategic Management Journal, 31(5): 547-561. 